\begin{tabular}{|c|c|c|}
\hline $\begin{array}{l}\text { PKS } \\
\text { PUBLIC } \\
\text { KNOWLEDGE } \\
\text { PROJECT }\end{array}$ & $\begin{array}{c}\text { REVISTA DE GEOGRAFIA } \\
\text { (RECIFE) } \\
\text { http://ww.revista.ufpe.br/revistageografia }\end{array}$ & $\begin{array}{l}\text { OJS } \\
\frac{\text { OPEN }}{\text { OPENAL }} \\
\text { SYSTEMS }\end{array}$ \\
\hline
\end{tabular}

\title{
UNIDADES DE CONSERVAÇÃO: ABORDAGENS E CARACTERÍSTICAS GEOGRÁFICAS
}

\author{
Márcio Balbino Cavalcante ${ }^{1}$ \\ ${ }^{1}$ Professor do Programa de Pós-Graduação Lato Sensu das Faculdades Integradas de Patos - FIP. E-mail: \\ cavalcantegeol@gmail.com
}

Artigo recebido em 31/07/2017 e aceito em 29/10/2017

\begin{abstract}
RESUMO
O livro "Unidades de Conservação: Abordagens e características geográficas", em questão, associa em sua discussão a tríade da Geografia Física, Geografia Humana e Ecologia Política, objetivando a compreensão das Unidades de Conservação (UCs) como territórios "vividos e "usados" e do campo de proteção da biodiversidade, a partir dos estudos de grupos sociais e da investigação de estratégias, práticas sociais e exercícios de poder, incluindo contradições, conflitos e negociação entre os atores e grupos sociais e esses espaços territoriais protegidos. Diante do contexto, a presente obra, que tem como organizadores os geógrafos-pesquisadores: Antonio José Teixeira Guerra e Maria Célia Nunes Coelho, reúne múltiplas pesquisas em UCs no âmbito da ciência geográfica, demonstrando que os profissionais geógrafos, particularmente auxiliados pelas ciências afins, podem contribuir para a compreensão das construções físicas, sociais e políticas ocorridas no contexto dos estudos das relações entre natureza e populações, sob perspectivas física, social, cultural e político-geográfica.

Palavras-chave: Resenha; Unidades de Conservação; Antonio José Teixeira Guerra; Maria Célia Nunes Coelho.
\end{abstract}

\section{CONSERVATION UNITS: GEOGRAPHICAL APPROACHES AND CHARACTERISTICS}

\begin{abstract}
The book "Unidades de Conservação: Abordagens e características geográficas", in question, associates in its discussion the triad of Physical Geography, Human Geography and Political Ecology, aiming at understanding the Conservation Units (UCs) as "lived and" used " and from the field of biodiversity protection, from the study of social groups and the investigation of strategies, social practices and power exercises, including contradictions, conflicts and negotiation between actors and social groups and these protected territorial spaces. Facing the context, the present work, which has as organizers the geographers-researchers: Antonio José Teixeira Guerra and Maria Célia Nunes Coelho, brings together multiple researches in UCs in the field of geographic science, demonstrating that geographers, particularly assisted by related sciences, can contribute to the understanding of the physical, social and political constructions that occur in the context of the study of the relations between nature and populations, under physical, social, cultural and political-geographic perspectives. Key-words: Review; Conservation units; Antonio José Teixeira Guerra; Maria Célia Nunes Coelho.
\end{abstract}

\section{RESENHA}

O livro "Unidades de Conservação: Abordagens e características geográficas”, em questão, associa em sua discussão a tríade da Geografia Física, Geografia Humana e Ecologia Política, objetivando a compreensão das Unidades de Conservação (UCs) como territórios "vividos e "usados" e do campo de proteção da biodiversidade, a partir dos estudos de grupos 
sociais (que para sobreviverem necessitam se territorializar e se organizar) e da investigação de estratégias, práticas sociais e exercícios de poder, incluindo contradições, conflitos e negociação entre os atores e grupos sociais e esses espaços territoriais protegidos (p.15).

Na atualidade, a criação das UCs é um dos principais instrumentos para a conservação da biodiversidade. No Brasil, as UCs são regulamentadas pelo o Sistema Nacional de Unidades de Conservação (SNUC), instituído pela Lei no 9. 985, de 18 de julho de 2000. Segundo o SNUC, essas áreas protegidas são compreendidas como espaços territoriais e seus componentes, incluindo as águas jurisdicionais, com características naturais relevantes, de domínio público ou privado, legalmente instituídos pelo Poder Público, com objetivos de conservação e de limites definidos, sob regime especial de administração, às quais se aplicam garantias adequadas de proteção (BRASIL, 2000).

Partindo desta assertiva, esta lei estabelece critérios e normas para criação, implantação e gestão das UCs nos âmbitos federal, estadual e municipal. A mesma norma classifica as Unidades brasileiras em duas categorias de manejo, o primeiro grupo abrange as "Unidades de Proteção Integral" ou de uso indireto dos recursos naturais. O segundo grupo é constituído pelas “Unidades de Uso Sustentável” ou de uso direto dos recursos.

Diante do contexto, a presente obra, que tem como organizadores os geógrafospesquisadores: Antonio José Teixeira Guerra e Maria Célia Nunes Coelho, reúne múltiplas pesquisas em UCs no âmbito da ciência geográfica, demonstrando que os profissionais geógrafos, particularmente auxiliados pelas ciências afins, podem contribuir para a compreensão das construções físicas, sociais e políticas ocorridas no contexto dos estudos das relações entre natureza e populações, sob perspectivas física, social, cultural e políticogeográfica (p.13).

Desta maneira, o livro supracitado está organizado em 7 (sete) capítulos que discutem problemáticas ligadas as Unidades de Conservação no âmbito brasileiro. A saber:

O primeiro Capítulo, intitulado: "Gestão da Biodiversidade e Áreas Protegidas", redigido pelos biólogos Evaristo de Castro Jr., Bruno Henrique Coutinho e Leonardo Esteves de Freitas, abordam as problemáticas contemporâneas relativas à instituição de áreas naturais protegidas e o despertar pelo interesse pela preservação da natureza, considerando os aspectos da política institucional da conservação e gestão territorial da biodiversidade no caso brasileiro.

No caso do Brasil, o Estado sempre foi o condutor da política de implantação e gestão de áreas protegidas, mesmo quando marcadas por processos de mobilização popular. Para 
Castro Júnior et al., (2015, p. 47), no texto “Gestão da Biodiversidade e Áreas Protegidas", até fins da década de 1980, "esse papel era fruto de uma visão de apropriação de recursos naturais e controle territorial". Desde então, esses autores argumentam que a perspectiva do Estado brasileiro viria se alterando ao incorporar a "noção estratégica de meio ambiente", na qual a biodiversidade passa a ser o conceito central na política de conservação.

O segundo capítulo redigido por Maria Célia Nunes Coelho, Luis Henrique Cunha e Maurílio de Abreu Monteiro, "Unidades de Conservação: populações, recursos e territórios abordagens da geografia e da ecologia política", objetiva compreender as instituições das Unidades protegidas e refletir sobre essas relações, discussões sobre população, território e proteção da natureza (p. 70), bem como interpretar as dificuldades de planejamento e gestão desses espaços protegidos na Amazônia brasileira.

Em seguida, o Capítulo 3: “APA de Petrópolis: um estudo das características geográficas" redigidos pelos geógrafos Antonio José Teixeira Guerra e Patrícia Batista Melo Lopes, partindo do princípio de que "aplicando métodos que lhes são próprios, os geógrafos examinam as unidades de conservação ou proteção ambiental, buscando estabelecer elos entre a geografia física e a geografia humana [...] (p. 113), enfatiza em sua pesquisa uma descrição do meio físico e levanta questões importantes sobre os impactos da expansão das áreas urbanas próximas de uma Área de Proteção Ambiental (APA) na cidade de Petrópolis e seu entorno, envolvendo desde especulação imobiliária para construção de luxuosos condomínios até os avanços das favelas em direção àquela área, principalmente, os terrenos de encostas.

O Capítulo 4, intitulado: "O Parque Nacional no Maciço da Tijuca: uma Unidade de Conservação na Metrópole do Rio de Janeiro", as autoras Ana Luiza Coelho Netto, Lia Osório Machado e a bióloga Rita de Cássia Martins Montezuma, comenta sobre as mudanças ocorridas no Maciço da Tijuca, Localizado no município do Rio de Janeiro, considerando suas características geoambientais e sua ocupação, focando nas fragmentações florestais. O Maciço é para elas como um "geoecossistema florestal-urbano" (p. 143), em seguida, justifica-se sua heterogeneidade das formações vegetais oriundas de sucessões naturais ou induzidas pela ação humana, encontradas no momento da Unidade supracitada, em 1961.

O Capítulo seguinte, intitula-se "Legislação Ambiental e a Gestão de Unidades de Conservação: o caso do Parque Nacional da Restinga de Jurubatiba-RJ", escrito pelas geógrafas Claudia Blanco de Dios e a geóloga Mônica dos Santos Marçal, defende a ideia de que a proteção legal não tem sido suficiente para manter a integridade das UC, onde a situação é ainda bastante precária. Para tal afirmação, as autoras comparam o arcabouço legal 
que incide sobre a referida Unidade juntamente com a realidade local e os problemas e conflitos enfrentados para o planejamento e gestão daquele espaço protegido. Constatam-se ainda, que a criação da referida UC influiu diretamente no ritmo de vida da localidade, particularmente na economia, pela vinculação histórica daquelas comunidades com as quais existe a extração de recursos naturais daquela área.

No Capítulo 6, intitulado "Caracterização e análise de situações ambientais relevantes no Parque Nacional dos Lençóis Maranhenses e áreas vizinhas", os pesquisadores Jorge Hamilton Souza dos Santos, Jorge Xavier da Silva e Nádja Furtado Bessa dos Santos, propõem apresentar uma caracterização geoambiental da área em estudo, bem como análise de situações ambientais relacionadas à migração das dunas e à cobertura vegetal, em parte do setor sudeste do mencionado parque (p. 203). Nesse contexto, busca subsidiar a tomada de decisões quanto à gestão daquela UC, mas o que está evidente é a completa insuficiência das normas estabelecidas no Plano de Manejo daquela Unidade.

O Capitulo final, intitulado: "Parque Estadual da Pedra Branca: o desafio da gestão de uma Unidade de Conservação em área urbana", das autoras Josilda Rodrigues da Silva Moura e Vivian Castilho da Costa, retoma os estudos de áreas protegias em espaço fluminense, em especial, o Parque Estadual da Pedra Branca (PEPB), as autoras argumentam que sua gestão é um dos grandes desafios da Unidade, principalmente devido à proximidade das áreas urbanas de uma metrópole (p.231). Ressalta-se na análise que práticas consideradas "tradicionais" para comunidades da região, como o plantio de banana e criação de gado, acabavam sendo utilizados como instrumentos para delimitação de propriedades irregulares invadindo os limites do referido Parque, mascarando o verdadeiro uso que se fazia: ocupação e retirada de madeira nativa. Essas ocupações irregulares são favorecidas pelas dificuldades de regularização fundiária do Parque, e por outro lado, da falta de política pública de habitação para a cidade do Rio de Janeiro, que lança grande contingente populacional para as zonas periféricas.

Diante do exposto, a proposta deste livro enraizadas em análise de variadas situações em diferentes escalas, experiências e contextos geográficos e ambientais, trilha o caminho da problemática da gestão e do planejamento das UCs no território brasileiro. É sem dúvida, uma proposta corajosa a partir da Geografia e que, certamente, trará importantes contribuições para a políticas e ações democráticas capazes de superar o falso dilema entre conservação da natureza e desenvolvimento e de permitir que finalmente a população brasileira se beneficie de seu rico patrimônio natural. 
Uma vez que considera fundamental a implementação de um planejamento territorial pautado em ferramentas metodológicas e instrumentos de gestão que procurem conciliar conservação ambiental e uso dessas áreas, levando em consideração os anseios das comunidades locais que residem no entorno dos espaços protegidos, a saber: construção do Plano de Manejo; elaboração do zoneamento ambiental; criação de Conselho Consultivo; estudos de capacidade de carga; formação de guias e guarda-parques; promoção de projetos e ações de educação e interpretação ambiental.

Frente a estas questões, compreende-se que é de extrema importância a leitura do livro na íntegra pelo público interessado na temática ambiental, tais como: professores em geral, pesquisadores, alunos de pós-graduação e de graduação, consultores ambientais, membros de ONGs, técnicos do Instituto Chico Mendes de Conservação da Biodiversidade (ICMBio), Instituto Brasileiro do Meio Ambiente e dos Recursos Naturais Renováveis (IBAMA), das secretarias municipais e estaduais de meio ambiente, bem como gestores e fiscais de unidades de conservação.

\section{REFERÊNCIAS}

BRASIL. Lei $\mathrm{n}^{\circ}$ 9.985, de 18 de julho de 2000. Sistema Nacional de Unidades de Conservação - SNUC. Brasília: PLANALTO, 2002. Disponível em:

< http://www.planalto.gov.br/civil_03/LEIS/L9985.htm >. Acesso em 30 mai. 2017.

CASTRO JÚNIOR, Evaristo de; COUTINHO, Bruno Henriques; FREITAS, Leonardo Esteves. Gestão da Biodiversidade e Áreas Protegidas. In: GUERRA, Antonio José Teixeira; COELHO, Maria Célia Nunes. (Orgs.). Unidades de Conservação: abordagens e características geográficas. Rio de Janeiro: Bertrand Brasil, 2015.

GUERRA, Antonio José Teixeira; COELHO, Maria Célia Nunes. (Orgs.). Unidades de Conservação: abordagens e características geográficas. 3. ed. Rio de Janeiro: Bertrand Brasil, 2015. 296p. 